\section{Speckle tracking ultrasonography as a new tool to assess diaphragmatic function: a feasibility study}

\author{
Sebastian Johannes Fritsch', Nima Hatam², Andreas Goetzenich², Gernot Marx', \\ Rüdiger Autschbach ${ }^{2}$, Leo Heunks ${ }^{3}$, Johannes Bickenbach ${ }^{1 *}$, Christian Simon Bruells ${ }^{4 *}$ \\ Departments of ${ }^{1}$ Intensive Care Medicine and ${ }^{2}$ Thoracic and Cardio-Vascular Surgery, \\ University Hospital RWTH Aachen, Aachen, Germany; ${ }^{3}$ Department of Intensive Care \\ Medicine, Amsterdam UMC, Vrije Universiteit Amsterdam, Amsterdam, The Netherlands; \\ ${ }^{4}$ Department of Anesthesiology, University Hospital RWTH Aachen, Aachen, Germany
}

A reliable method of measuring diaphragmatic function at the bedside is still lacking. Widely used two-dimensional (2D) ultrasonographic measurements, such as diaphragm excursion, diaphragm thickness, and fractional thickening (FT) have failed to show clear correlations with diaphragmatic function. A reason for this is that $2 \mathrm{D}$ ultrasonographic measurements, like $\mathrm{FT}$, are merely able to measure the deformation of muscular diaphragmatic tissue in the transverse direction, while longitudinal measurements in the direction of contracting muscle fibres are not possible. Speckle tracking ultrasonography, which is widely used in cardiac imaging, overcomes this disadvantage and allows observations of movement in the direction of the contracting muscle fibres, approximating muscle deformation and the deformation velocity. Several studies have evaluated speckle tracking as a promising method to assess diaphragm contractility in healthy subjects. This technical note demonstrates the feasibility of speckle tracking ultrasonography of the diaphragm in a group of 20 patients after an aortocoronary bypass graft procedure. The results presented herein suggest that speckle tracking ultrasonography is able to depict alterations in diaphragmatic function after surgery better than 2D ultrasonographic measurements.

Keywords: Diaphragm; Ultrasonography; Speckle tracking ultrasound; Fractional thickening Key points: A reliable sonographic measurement method for bedside assessment of diaphragmatic function is still lacking. We could show that speckle tracking sonography is a feasible method for assessing diaphragmatic function in a clinical setting. Measuring diaphragmatic contractility using speckle tracking provides new insights into postoperative changes in diaphragmatic function better than 2D sonographic measurements.

\section{Introduction}

Ultrasonography is of increasing interest for the bedside examination of diaphragmatic function. Currently, mainly two-dimensional (2D) measures, such as diaphragm excursion, diaphragm

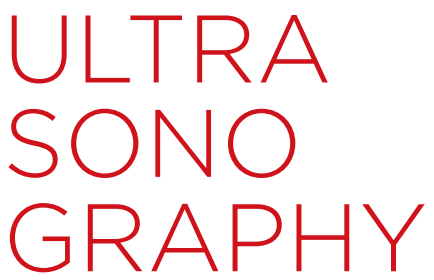

\section{TECHNICAL NOTE}

https://doi.org/10.14366/usg.21044 pISSN: 2288-5919・elSSN: 2288-5943 Ultrasonography 2022;41:403-415

Received: February 25, 2021

Revised: August 16, 2021

Accepted: August 17, 2021

Correspondence to:

Sebastian Johannes Fritsch, MD, Department of Intensive Care Medicine, University Hospital RWTH Aachen, Pauwelsstr. 30, 52074 Aachen, Germany

Tel. +49-241-8080444

Fax. +49-241-803380444

E-mail: sfritsch@ukaachen.de

*These authors contributed equally to this work.

This is an Open Access article distributed under the terms of the Creative Commons Attribution NonCommercial License (http://creativecommons.org/ licenses/by-nc/4.0/) which permits unrestricted noncommercial use, distribution, and reproduction in any medium, provided the original work is properly cited.

Copyright (C) 2022 Korean Society of Ultrasound in Medicine (KSUM)

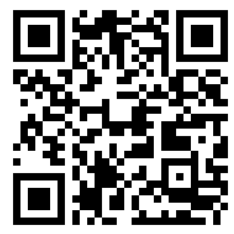

How to cite this article:

Fritsch SJ, Hatam N, Goetzenich A, Marx G, Autschbach R, Heunks L, et al. Speckle tracking ultrasonography as a new tool to assess diaphragmatic function: a feasibility study. Ultrasonography. 2022 Apr;41(2):403415. 
thickness, and fractional thickening (FT) are used [1]. However, doubts regarding the reliability of these methods prompted a search for better alternatives. Existing measurements are merely able to measure the deformation of muscular diaphragmatic tissue in the transverse direction, while longitudinal measurements in the direction of contraction are not possible [2]. Speckle tracking ultrasonography, which is widely used in cardiac imaging, overcomes this disadvantage and allows observations of movement in the direction of the contracting muscle fibres. The algorithm follows small regions of the ultrasonographic image with a unique pattern of different echogenic spots from frame to frame, thus "tracking" them. The depicted movement of speckles represents the correlate of ultrasound interference inside the tissue and their movement towards each structure. It reflects myofibrils/muscle tissue during movement (i.e., contraction/relaxation), approximating contractile function $[3,4]$. The "strain" parameter approximates muscle deformation, while "strain rate" measures the deformation velocity $[5,6]$. In several studies, speckle tracking has been evaluated as a promising method to assess the diaphragm contractility in healthy subjects $[2,7-10]$.

After cardiac surgery, patients often show alterations of the diaphragmatic contraction pattern, resulting in a clinically wellknown reduction of diaphragmatic function $[11,12]$ occurring in up to $85 \%$ of patients [13]. Several studies using conventional ultrasonographic methods to examine the diaphragm have been conducted in this patient group $[14,15]$.

For the present study, it was hypothesized that it would be possible to demonstrate diaphragmatic dysfunction after cardiac surgery using speckle tracking ultrasonography of the diaphragm, and that dysfunction would manifest as a decrease of the strain and strain rate parameters. A second hypothesis was that the results of diaphragmatic 2D ultrasonography could be correlated with those derived from speckle tracking ultrasonography. Taken together, the present study aimed to explore the feasibility of speckle tracking ultrasonography for an evaluation of the diaphragm in a clinical setting.

\section{Materials and Methods}

\section{Compliance with Ethical Standards}

The present study was approved by the local Ethics Committee at the RWTH Aachen University Faculty of Medicine (EK 317/15). Written consent was obtained before patients were included in the study.

\section{Study Protocol and Patient Enrolment}

In March 2017, 20 adult patients scheduled for elective coronary artery bypass graft ( $C A B G$ ) were enrolled. The exclusion criteria were pregnancy and sepsis (preoperative or perioperative). A flowchart of the study population is given in Fig. 1. The study population comprised $18(90 \%)$ men and two women, with a mean age of 63.9 years (range, 52 to 81 years). After surgery, sedation was maintained in the intensive care unit (ICU) until patients reached the required criteria for weaning from mechanical ventilation. Extubation was carried out by the ICU physician on duty as per standard institutional procedures. Clinical parameters with a potential impact on the function of the diaphragm were recorded and examined to assess their relationships with the values of the ultrasonographic assessment. Those parameters included preoperative and postoperative left ventricular cardiac function, which was categorised visually as normal or impaired (three levels of severity), as well as sociodemographic data, past medical history, the duration of surgery and mechanical ventilation, and fluid balance.

\section{Ultrasonographic Assessments}

Each patient received three ultrasonographic assessments: (1) preoperatively, (2) within 24 hours, and (3) within 48 hours after extubation. Patients were placed in a $30^{\circ}$ upright position and breathed spontaneously during the examinations. Ultrasound loops were recorded during tidal breathing and a voluntary maximal inspiratory manoeuvre. All assessments were performed by the same examiner. Ultrasonography of the diaphragm was performed using a 9-MHz linear transducer on a Vivid $\mathrm{E} 9$ ultrasound device (General Electric Healthcare, Horten, Norway), which was positioned in the zone of apposition (eighth to 11th intercostal spaces) of the right hemithorax between the anterior axillary and the mid-axillary line longitudinal to the body axis. Two echogenic lines (pleura and peritoneum) above the liver tissue marked the diaphragm as the layer between them (Fig. 2). The penetration depth and focus were adjusted optimally and respiratory curves derived from electrocardiography were merged with the ultrasound picture. The cineloops were saved and analysed offline.

\section{Offline Analysis}

We used the EchoPac software (version 113, revision 1.0; General Electric Healthcare, Boston, MA, USA) for post hoc analysis.

FT was calculated using the following equation: (end-inspiratory thickness-end-expiratory thickness)/end-expiratory thickness. The diaphragmatic thickness was measured at the same anatomic position following the longitudinal downward motion of the respective location over all breaths of an entire cineloop. Only one of the hyperechogenic lines (usually the pleura) was included in the measured distance.

The Q-analysis tool of the EchoPac software was used to analyse 




Fig. 1. Flowchart of the patient population. The flowchart shows the course of examined patient numbers in the present feasibility study over time. Additionally, it shows the number of patients excluded with the respective reasons. CABG, coronary artery bypass graft; ST, speckle tracking.

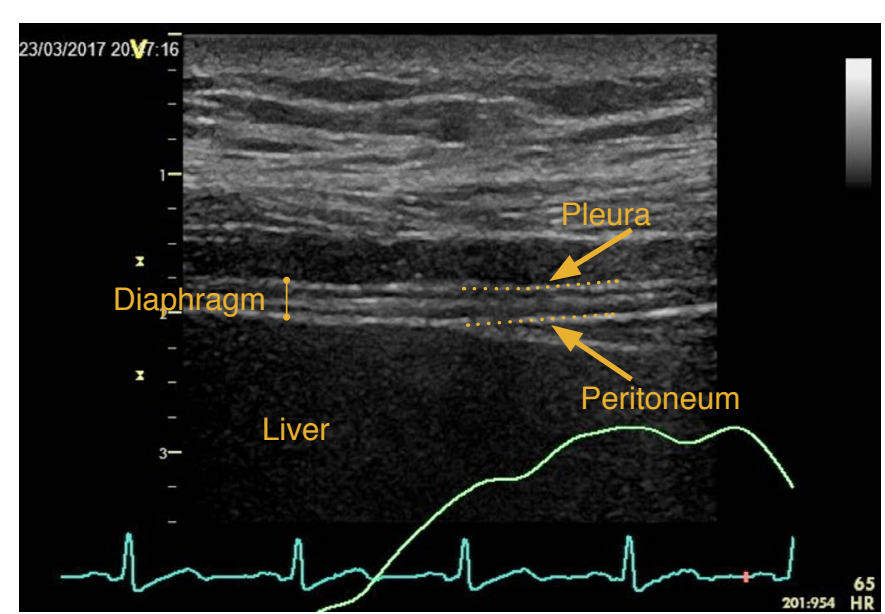

Fig. 2. Ultrasonographic imaging of the diaphragm recorded in B-mode in the zone of apposition. The diaphragm is displayed between the two echogenic lines above the liver tissue, which represent the pleura and peritoneum.

the recorded ultrasound data with the speckle tracking technique using the 2D strain modality. Under basal respiration, at least three loops per examination were included in the analysis. Under forced inspiration, all analysable loops were included. The loop was adjusted to cover one entire breathing cycle. A region of interest (ROI) was manually drawn on a representative part of the diaphragm along one echogenic line. After placing the ROI in the longitudinal direction, the transverse dimension was adjusted. If required, the ROI was manually aligned with the borders of the diaphragmatic layer. The software then calculated the inspiratory peak strain and the inspiratory peak strain rate as parameters for longitudinal deformation (Fig. 3, Video clip 1). The longitudinal strain represents the relative change in length compared to an initial reference state $(\%)$, while the strain rate represents the velocity of deformation $(1 / s)$, which is independent of the referential state. In both cases, an increase in deformation and velocity is connected to a more negative parameter value. The tool for the analysis of transverse strain and strain rate was not available in the software version that was used. If the image quality was insufficient or successful tracking could not be obtained after several attempts, pictures were excluded from analysis.

\section{Statistics}

SPSS version 25 (IBM Corp., Armonk, NY, USA) was used for statistical analysis. Assessments in basal respiration and forced inspiration were analysed separately in terms of absolute values and relative to the initial values, as the postoperative value divided by the preoperative value for each patient. The non-parametric 


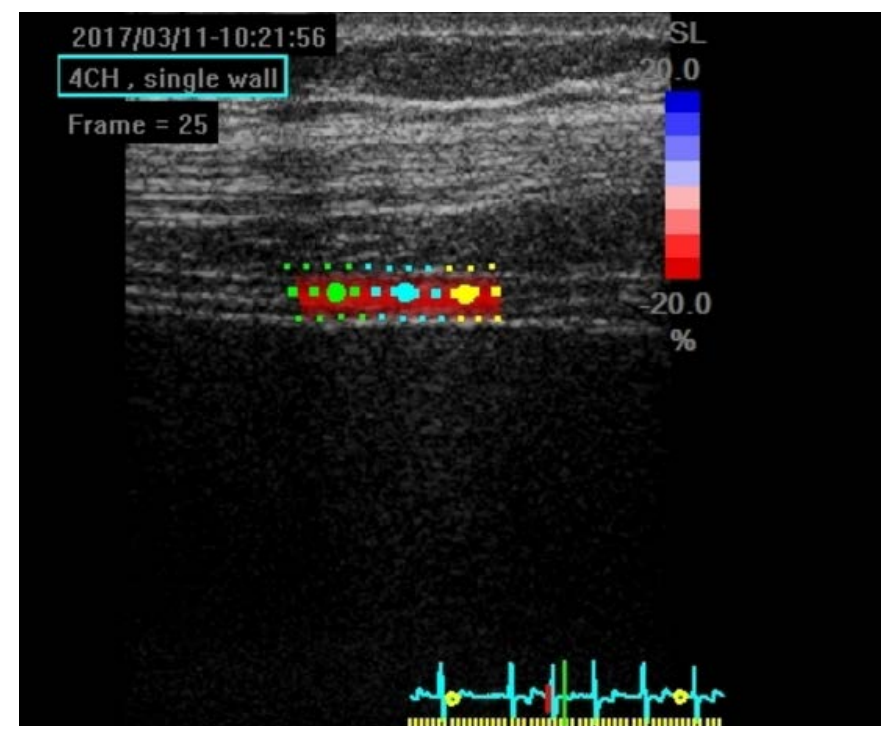

A

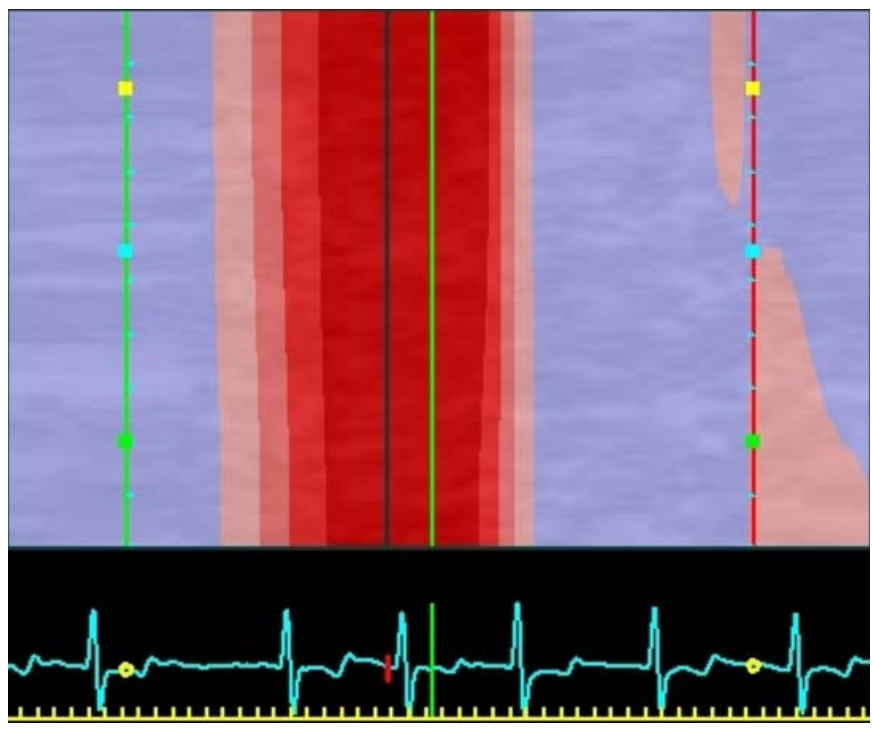

B

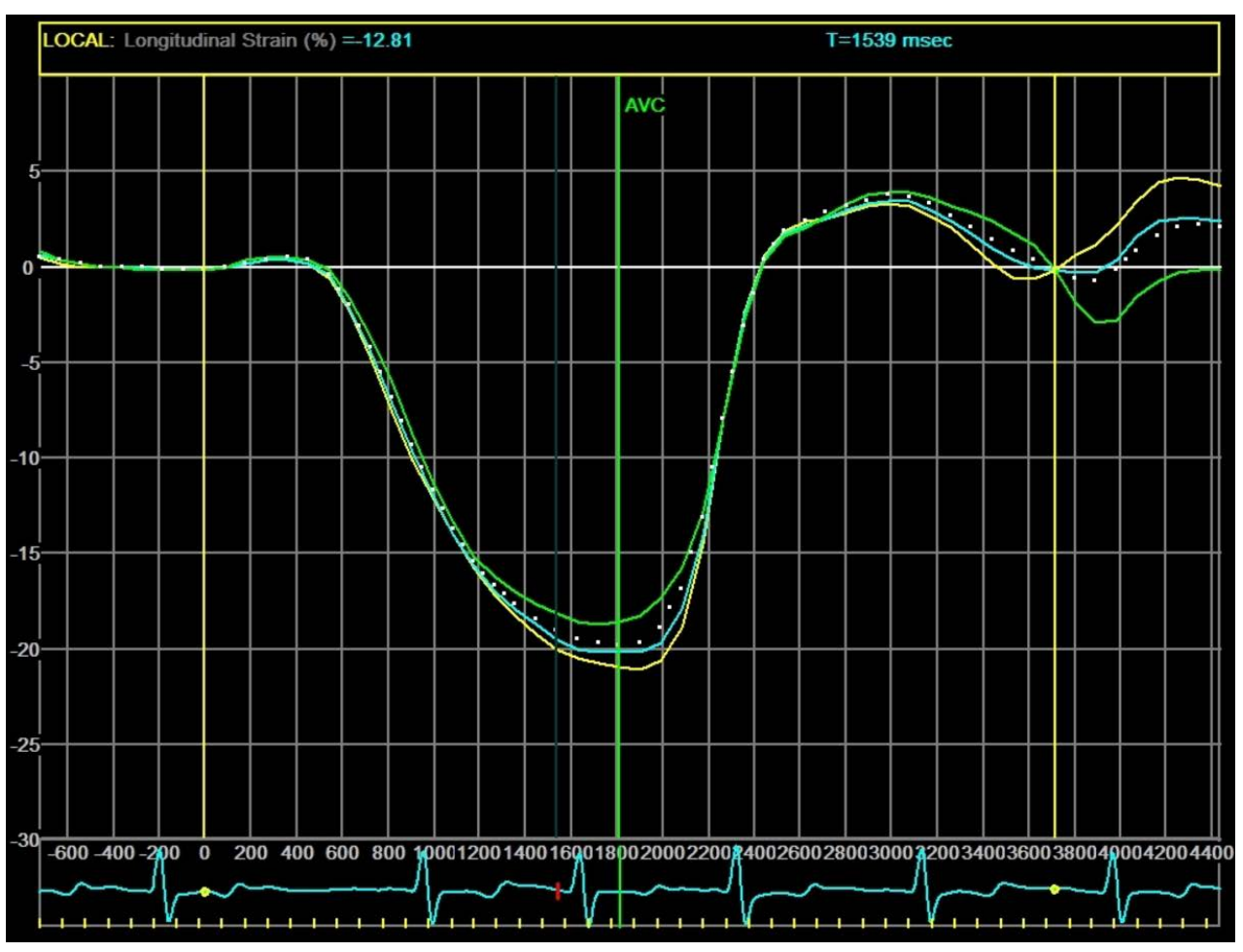

C

Friedman rank-sum test and Wilcoxon-Nemenyi-McDonaldThompson multiple comparisons were calculated for all pairs of data for the outcome variables (strain, strain rate, and FT) as post-hoc tests. The correlations between speckle tracking measurements and administered fluids were calculated using the Spearman method. Two-tailed P-values less than 0.05 were considered to indicate statistical significance.
Fig. 3. A screenshot of the Q-analysis tool of the EchoPac software.

A. The subscreen shows a B-mode picture of the diaphragm with the respective regions of interest. $B$. This diagram visualizes contraction in relation to time ( $\mathrm{x}$-axis) and localization in the respective region of interest (ROI) (y-axis). C. The main graphs represent the strain values of the different ROls over the course of one breathing cycle.

\section{Results}

\section{Patient Characteristics and Clinical Course}

Patients' characteristics are given in Table 1. Two patients withdrew their consent at different timepoints. One patient suffering from prolonged thoracic bleeding in the ICU had to undergo redo surgery. All patients could be weaned from the ventilator within 26 hours 
Table 1. Characteristics of the 20 patients in this study

\begin{tabular}{lc}
\multicolumn{1}{c}{ Characteristic } & Value \\
\hline Age (year) & $63.9 \pm 7.3$ \\
Male sex & $18(90.0)$ \\
BMI $\left(\mathrm{kg} / \mathrm{m}^{2}\right)$ & $27.4 \pm 2.9$ \\
$25-30$ (overweight) & $11(55.0)$ \\
$>30$ (obesity) & $5(25.0)$ \\
Medical conditions & \\
Coronary heart disease & $20(100)$ \\
Atrial fibrillation & $5(25.0)$ \\
Arterial hypertension & $16(80.0)$ \\
Chronic obstructive pulmonary disease & $3(15.0)$ \\
Obstructive sleep apnoea syndrome & $2(10.0)$ \\
Left-ventricular function, preoperative & \\
Normal & $11(55.0)$ \\
Mildly impaired & $4(20.0)$ \\
Moderately impaired & $1(5.0)$ \\
Severely impaired & $2(10.0)$ \\
N/A & $2(10.0)$
\end{tabular}

Left-ventricular function, postoperative

\begin{tabular}{|c|c|}
\hline Normal & $14(70.0)$ \\
\hline Mildly impaired & $3(15.0)$ \\
\hline Moderately impaired & $2(10.0)$ \\
\hline Severely impaired & 0 \\
\hline N/A & $1(5.0)$ \\
\hline Duration of surgery (hh:mm) & $5: 05 \pm 0: 54$ \\
\hline Perfusion time (hh:mm) & $\begin{array}{c}1: 38 \pm 0: 31 \\
\text { (1 off pump) }\end{array}$ \\
\hline Duration of mechanical ventilation (OR+ICU) (hh:mm) & $16: 40 \pm 6: 23$ \\
\hline Thereof assisted spontaneous breathing & $1: 22 \pm 1: 24$ \\
\hline $\begin{array}{l}\text { Time between extubation and first ultrasonographic } \\
\text { assessment (hh:mm) }\end{array}$ & $8: 35 \pm 04: 20$ \\
\hline $\begin{array}{l}\text { Time between extubation and second } \\
\text { ultrasonographic assessment (hh:mm) }\end{array}$ & $37: 44 \pm 6: 50$ \\
\hline $\begin{array}{l}\text { Received intravenous fluids within the first } 24 \text { hours } \\
\text { in the ICU (mL) }\end{array}$ & $3,414 \pm 1,463$ \\
\hline
\end{tabular}

after ICU admission. No reintubation was required. The mean duration of mechanical ventilation was 16 hours and 40 minutes (standard deviation, \pm 6 hours and 23 minutes).

\section{Feasibility}

Eighteen patients completed all examinations within the scheduled timeframe. In general, the pictures were acquired at bedside within 5 minutes. No patient voiced any complaints or signs of discomfort during the procedure. A successful analysis was possible in $96.5 \%$ $(55 / 57)$ of the recorded ultrasonographic loops under basal respiration and $82.5 \%(47 / 57)$ of those under forced respiration. For a set of three sequential cineloops acquired in a single patient, please see Video clips 2-4 with the corresponding analysis in Supplementary Fig. 1.

\section{Ultrasonographic Analysis of the Diaphragm}

The results of the ultrasonographic assessment of the diaphragm are given in Table 2. P-values for the comparisons of the ultrasonographic parameters between the different assessments are given in Table 3.

\section{Strain under basal respiration}

Within 24 hours after extubation, all patients showed a decrease of strain under basal respiration (Fig. 4A, C). The median strain decreased to $73 \%$ of the preoperative value. Within 48 hours after extubation, all patients recovered to strain values near the preoperative status. The decrease from the first to second assessment and the increase from the second to third assessment were both statistically significant ( $\mathrm{P}<0.001$ for both comparisons).

\section{Strain rate under basal respiration}

Postoperatively, the median strain rate remained nearly unchanged compared to the preoperative examination. However, several patients showed strong changes of this parameter in both directions, which only almost balanced each other in the sum. Remarkably, the median strain rate strongly increased 48 hours after extubation (Fig. 4B, D). All patients except one showed a full recovery to the preoperative condition or even a strain rate exceeding the preoperative values, with two of them showing a more than threefold increase. The increase of the third assessment was statistically significant compared to the preoperative values $(P=0.010)$ as well as to the first postoperative assessment $(P<0.001)$.

\section{Strain under forced inspiration}

Due to poor picture quality under the forced inspiration manoeuvre, only 14 patients could be analysed; the values of these patients changed non-homogeneously (Fig. 5A, C). Nonetheless, a majority of patients showed a strain pattern with early postoperative decrease and a subsequent recovery, comparable to basal respiration. However, not all patients recovered; those patients instead continued to have decreased strain 48 hours after extubation instead.

\section{Strain rate under forced inspiration}

Measurements of strain rate under forced respiration also generated non-homogeneous results (Fig. 5B, D). However, half of the 
Table 2. Results of the ultrasonographic assessment of diaphragmatic function

\begin{tabular}{|c|c|c|c|c|}
\hline & $\begin{array}{l}\text { First assessment } \\
\text { (preoperative) }\end{array}$ & $\begin{array}{c}\text { Second assessment } \\
\text { ( } 24 \text { hours after extubation) }\end{array}$ & $\begin{array}{c}\text { Third assessment } \\
\text { (48 hours after extubation) }\end{array}$ & P-value ${ }^{a)}$ \\
\hline \multicolumn{5}{|l|}{ Results in absolute values } \\
\hline \multicolumn{5}{|l|}{ Basal respiration } \\
\hline ST-Strain (\%) & $-20.78(5.54)$ & $-14.47(4.59)$ & $-19.36(4.60)$ & $<0.001$ \\
\hline ST-Strain rate (1/S) & $-0.41(0.27)$ & $-0.39(0.25)$ & $-0.58(0.25)$ & $<0.001$ \\
\hline Fractional thickening (\%) & $23.50(9.95)$ & $14.79(9.48)$ & $24.92(21.13)$ & 0.013 \\
\hline \multicolumn{5}{|l|}{ Forced respiration } \\
\hline ST-Strain (\%) & $-33.41(9.70)$ & $-24.67(7.43)$ & $-26.54(9.33)$ & 0.008 \\
\hline ST-Strain rate $(1 / \mathrm{s})$ & $-0.75(0.76)$ & $-0.81(0.59)$ & $-0.80(0.39)$ & 0.109 \\
\hline Fractional thickening (\%) & $50.0(29.71)$ & $23.63(29.76)$ & $34.44(46.59)$ & 0.050 \\
\hline \multicolumn{5}{|c|}{ Results in relative values normalized to the preoperative value } \\
\hline \multicolumn{5}{|l|}{ Basal respiration } \\
\hline ST-Strain (\%) & 1 & $0.73(0.31)$ & $0.995(0.17)$ & $<0.001$ \\
\hline ST-Strain rate (1/s) & 1 & $0.94(0.39)$ & $1.41(0.69)$ & $<0.001$ \\
\hline Fractional thickening (\%) & 1 & $0.72(0.45)$ & $1.14(1.43)$ & 0.013 \\
\hline \multicolumn{5}{|l|}{ Forced respiration } \\
\hline ST-Strain (\%) & 1 & $0.76(0.28)$ & $0.84(0.33)$ & 0.004 \\
\hline ST-Strain rate (1/s) & 1 & $0.87(1.18)$ & $1.06(1.40)$ & 0.109 \\
\hline Fractional thickening (\%) & 1 & $0.58(0.29)$ & $0.77(0.55)$ & 0.050 \\
\hline
\end{tabular}

Values are presented as median (IQR). For normalized results, absolute values were divided by the preoperative value for each patient.

$S T$, speckle tracking; IQR, interquartile range.

a) $\mathrm{P}$-value obtained comparing the distribution of the respective value on the three indicated time points using the non-parametric Friedman test.

Table 3. P-values of the comparisons of the ultrasonographic assessment for diaphragmatic function between the different time points

\begin{tabular}{|c|c|c|c|}
\hline & $\begin{array}{l}\text { Preoperative to } \\
24 \mathrm{~h} \text { post- } \\
\text { extubation }\end{array}$ & $\begin{array}{l}\text { Preoperative to } \\
48 \mathrm{~h} \text { post- } \\
\text { extubation }\end{array}$ & $\begin{array}{l}24 \mathrm{~h} \text { post- } \\
\text { extubation } \\
\text { to } 48 \mathrm{~h} \text { post- } \\
\text { extubation }\end{array}$ \\
\hline \multicolumn{4}{|l|}{ Basal respiration } \\
\hline ST-Strain & $<0.001^{\mathrm{a})}$ & 0.984 & $<0.001^{\mathrm{a})}$ \\
\hline ST-Strain rate & 0.667 & $0.010^{a)}$ & $<0.001^{\mathrm{a})}$ \\
\hline Fractional thickening & $0.022^{\mathrm{a})}$ & 0.981 & $0.037^{\mathrm{a})}$ \\
\hline \multicolumn{4}{|l|}{ Forced respiration } \\
\hline ST-Strain & $0.007^{\mathrm{a})}$ & 0.094 & 0.612 \\
\hline ST-Strain rate & 0.383 & 0.730 & 0.094 \\
\hline Fractional thickening & 0.116 & 0.966 & 0.495 \\
\hline
\end{tabular}

examined patients had a decreased strain rate within 24 hours after extubation, while the other half showed no changes or increased values. From the second to the third examination, the strain rate did not show relevant changes in the majority of patients. Patients with an increased strain rate postoperatively, in particular, still showed this deformation in velocity over time.

\section{Fractional thickening}

The median preoperative FT was $23.5 \%$ under basal respiration. Showing similar trends as the strain values, it decreased to $14.79 \%$ in the first postoperative examination and recovered, even exceeding the baseline, to a value of $24.92 \%$ in the second postoperative measurement (Fig. 6). There were statistically significant results for comparisons between the preoperative and the first postoperative measurements ( $P=0.022)$ and between the first and second postoperative evaluations ( $P=0.037$ ). Due to postoperative anatomical changes of the diaphragm and lung and insufficient picture recording, only 12 patients breathing under maximal inspirational force could be analysed. The FT under forced breathing before the surgical procedure was 50\%. Within the first 24 hours after extubation, the FT of forced respiration decreased to $23.63 \%$ and showed a slight recovery to $34.44 \%$ at the final examination. In contrast to our expectations, there were no clear correlations between strain, strain rate, and FT. 


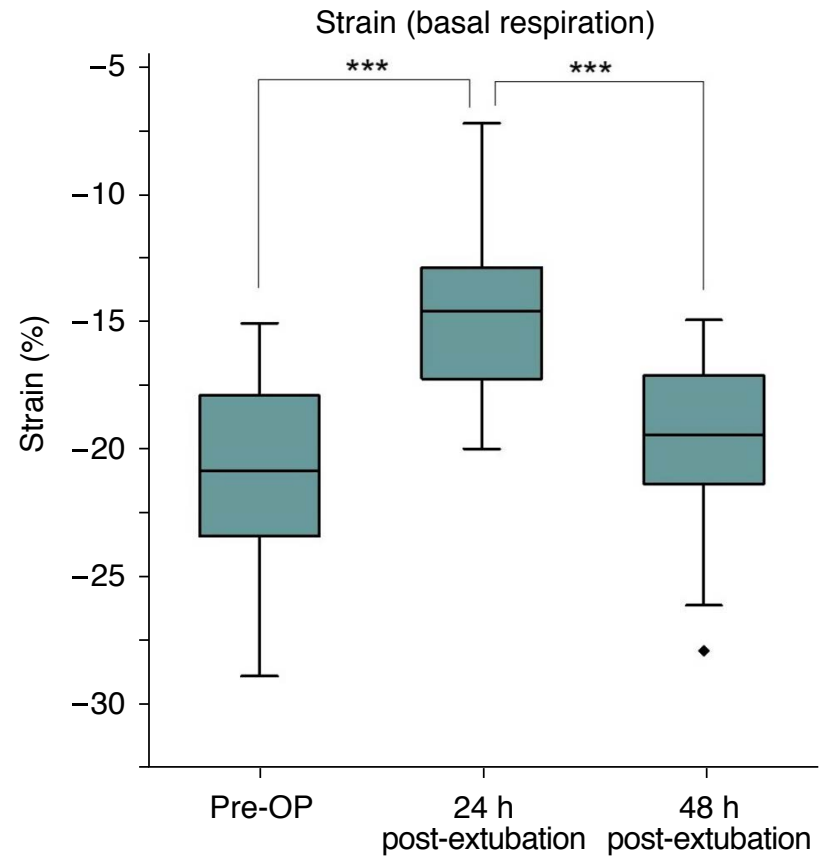

A

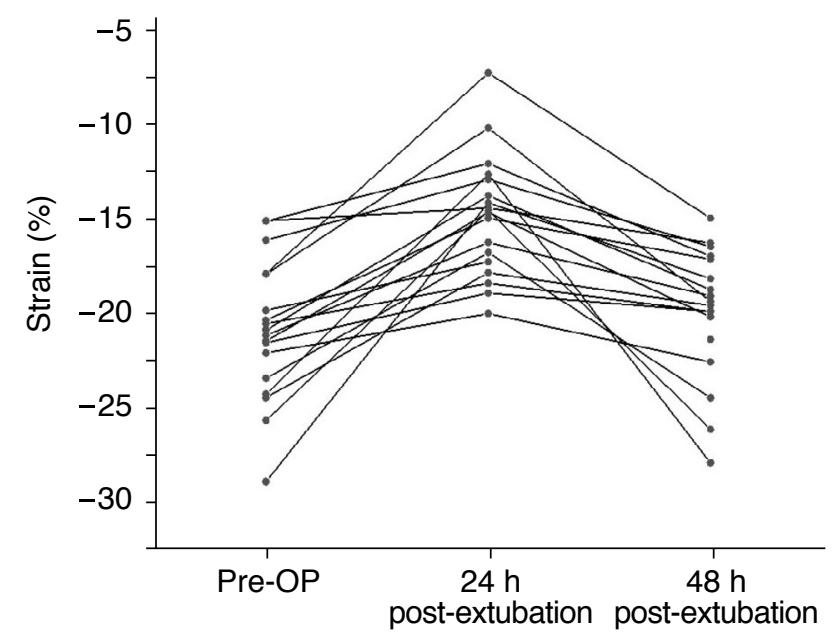

C

Fig. 4. Speckle tracking analysis of diaphragmatic movement under basal respiration.

$A, B$. The figures depict the values for strain and strain rate over time. The box indicates the interquartile range (IQR) and the median, the whiskers indicate 1.5 times the IQR and the dots indicate outliers (Nota bene: negative values represent contraction). C, D. Plots represent the individual data of all patients for strain and strain rate over the three measurements. P-values were calculated using the Nemenyi test. ${ }^{*} \mathrm{P}<0.05,{ }^{* *} \mathrm{P}<0.001$.

\section{Correlations with Clinical Parameters}

No correlation with the diaphragmatic function (represented by strain, strain rate, or FT) was found for age, body mass index, length of mechanical ventilation, preoperative or postoperative cardiac function, or pre-existing diseases. In addition, there was no statistical evidence for a link between the $\mathrm{PaO}_{2} / \mathrm{FiO}_{2}$ ratio, positive end-expiratory pressure, or the length of the cardiopulmonary bypass
Strain rate (basal respiration)

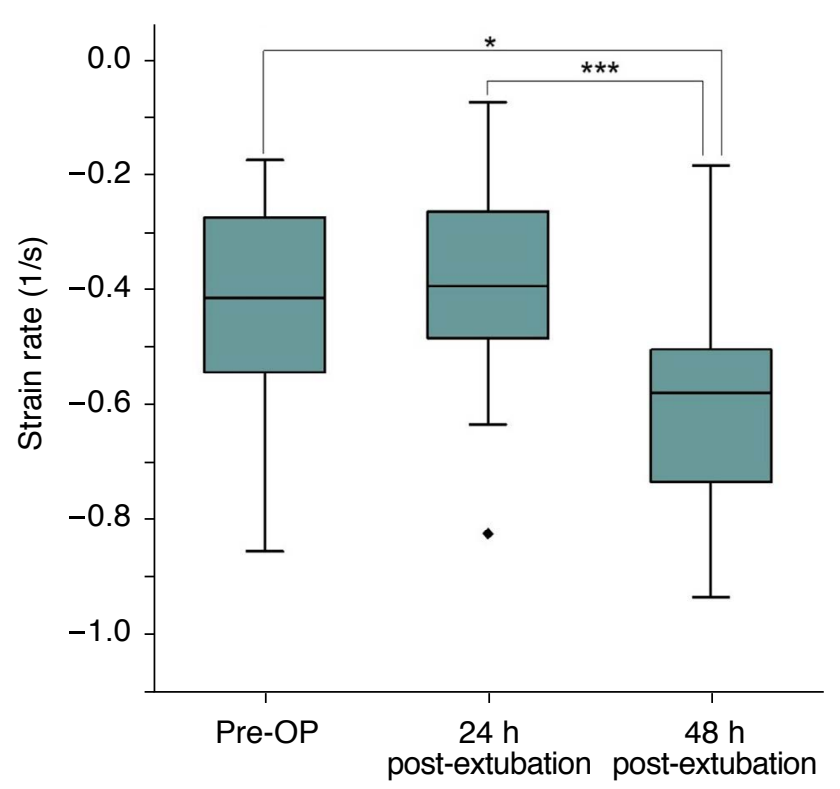

B

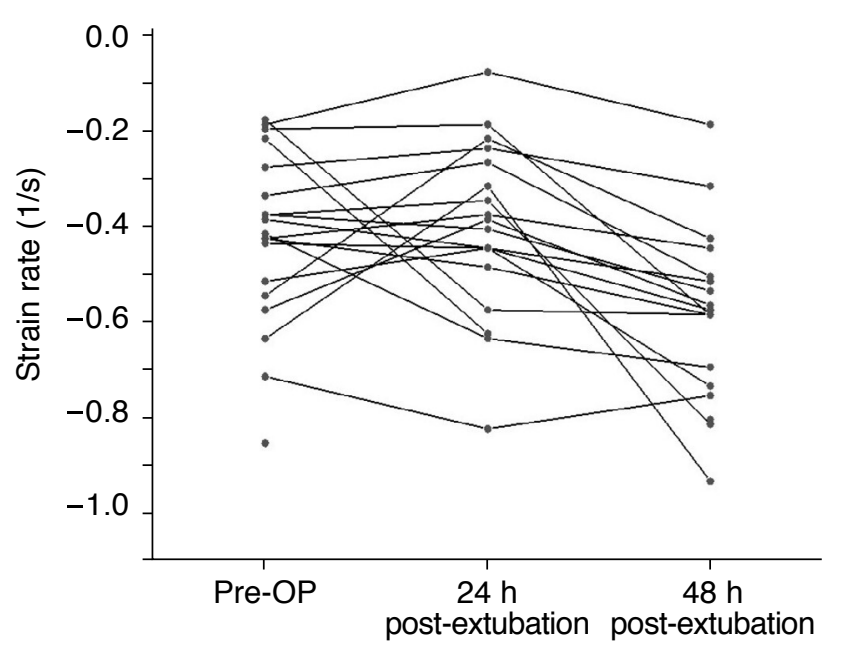

D 


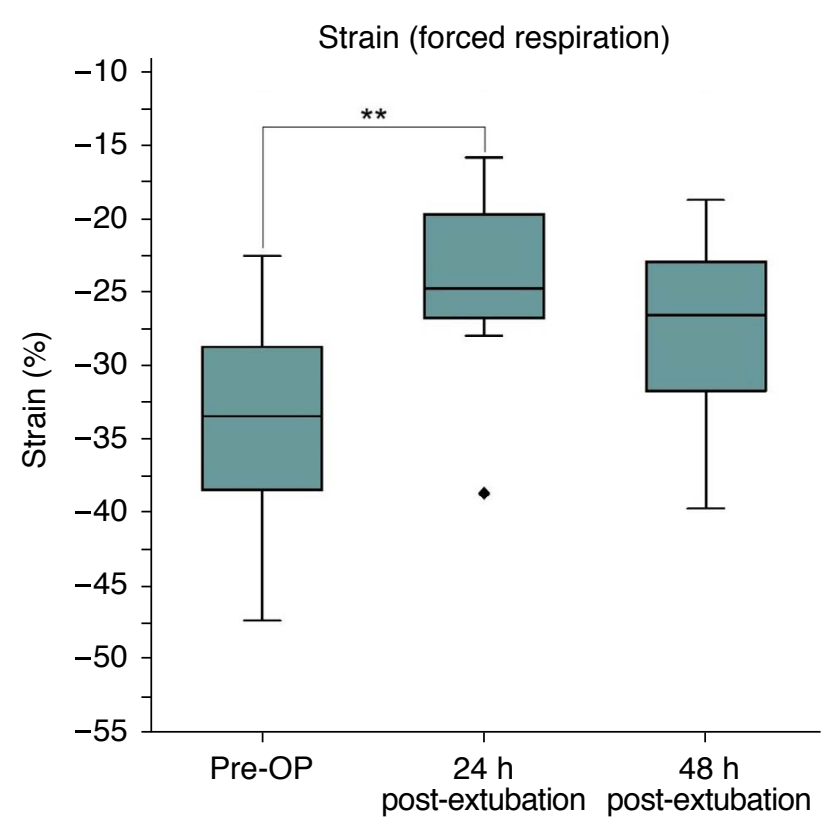

A

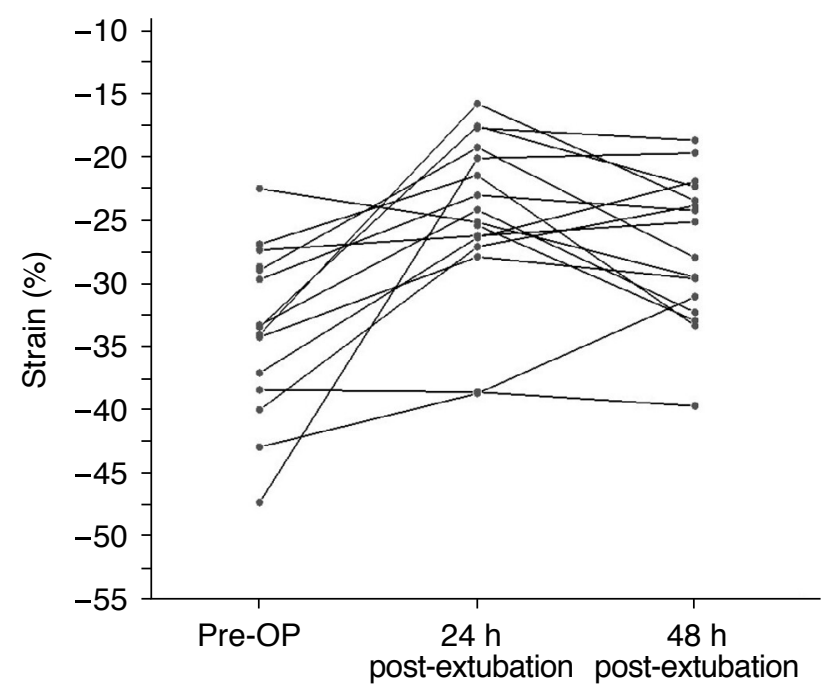

C

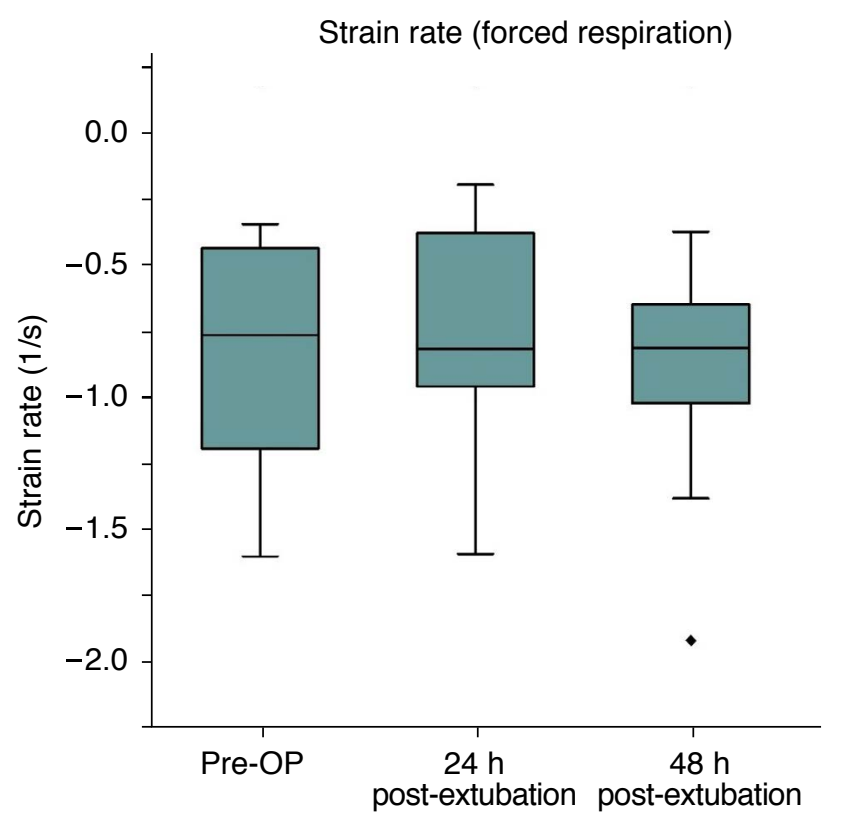

B

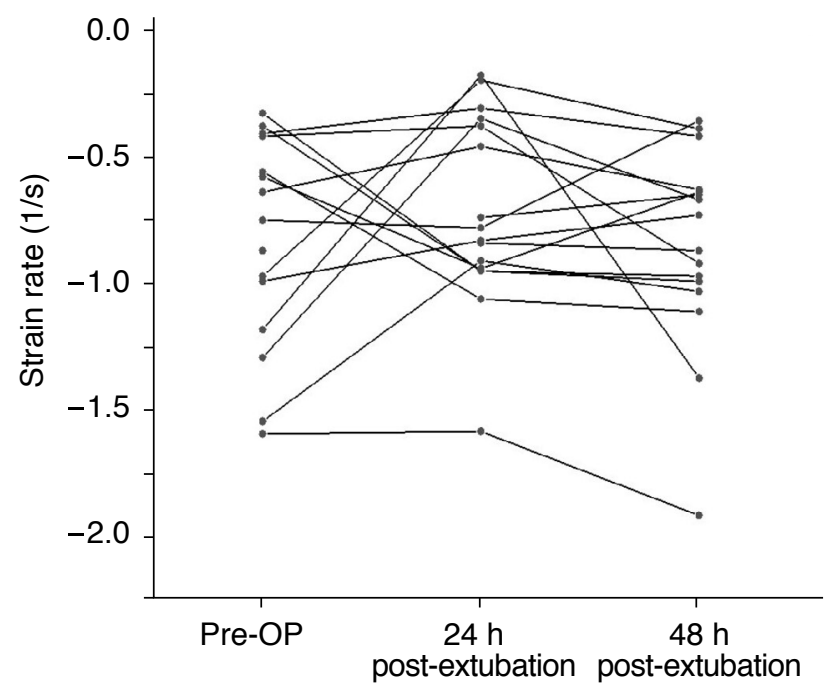

D

Fig. 5. Speckle tracking analysis of diaphragmatic movement under forced respiration.

$A, B$. The figures depict the values for strain and strain rate over the time. The box indicates the interquartile range $(I Q R)$ and the median, the whiskers indicate 1.5 times the IQR and the dots indicate outliers (Nota bene: negative values represent contraction). C, D. Plots represent the individual data of all patients for strain and strain rate over the three measurements. P-values were calculated using the Nemenyi test. ${ }^{*} \mathrm{P}<0.01$.

strain rate and volume was -0.495 . This correlation was statistically significant ( $\mathrm{P}=0.023$ for strain and $\mathrm{P}=0.037$ for strain rate). Twentyfour hours earlier, a vaguely similar effect was present, but without statistical significance. In contrast to these findings, there was no correlation between $\mathrm{FT}$ and volume balance.

\section{Discussion}

\section{General Findings}

To the best of our knowledge, this is the first study using speckle tracking ultrasonography to assess diaphragmatic function in ICU patients. The current gold standard for the examination of diaphragmatic function is the measurement of transdiaphragmatic 


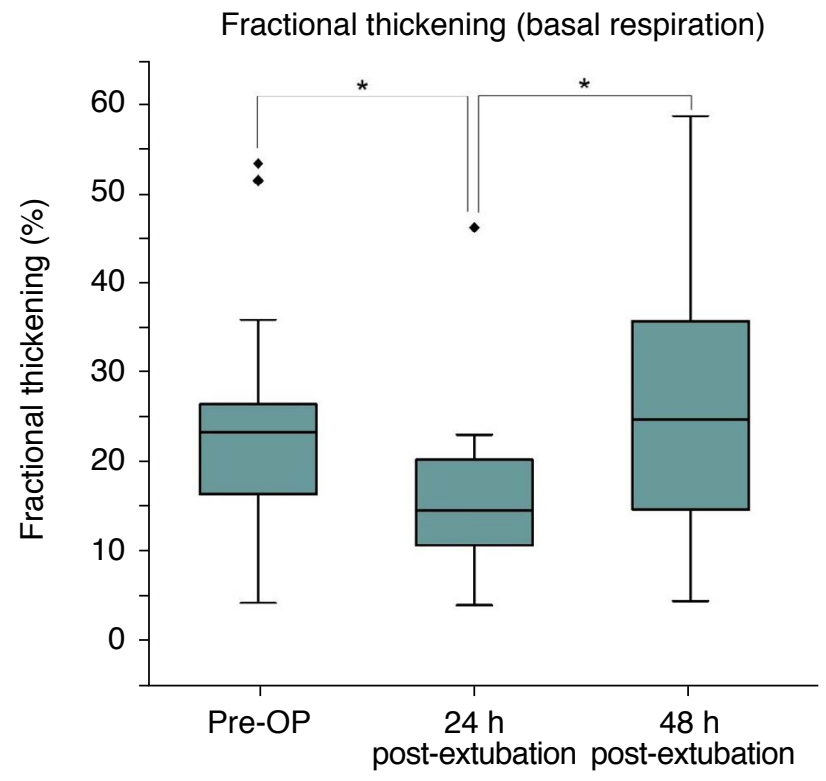

A

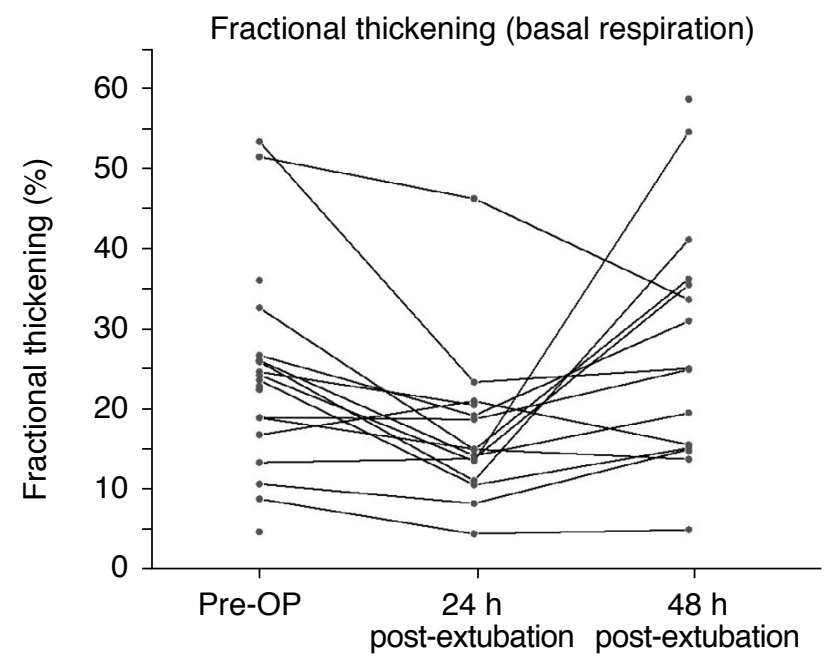

C

Fig. 6. Fractional thickening of the diaphragm.

$A, B$. The sub-figures show the values of fractional thickening under basal (A) and forced respiration (B). The box indicates the interquartile range (IQR) and the median, the whiskers indicate 1.5 times the IQR, and the dots indicate outliers. C, D. Plots represent the individual data of all patients for fractional thickening under basal (C) and forced respiration (D) over the three measurements. P-values were calculated using the Nemenyi test. ${ }^{*} \mathrm{P}<0.05$.

pressure (Pdi) or electric activity (EAdi). Previous studies have validated speckle tracking ultrasonography for the assessment of diaphragmatic function against Pdi and EAdi in healthy volunteers $[8,9]$, with these methods showing close correlations with each other. In the present study, we showed that the use of speckle tracking is also feasible in a clinical setting. The perceived results support the well-known clinical observation of decreased

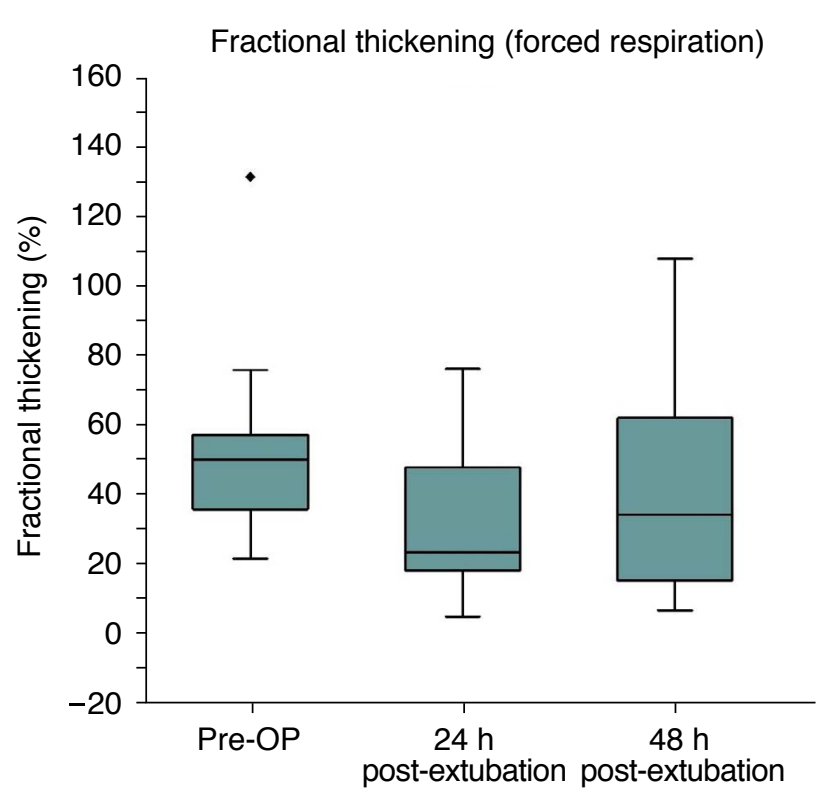

B

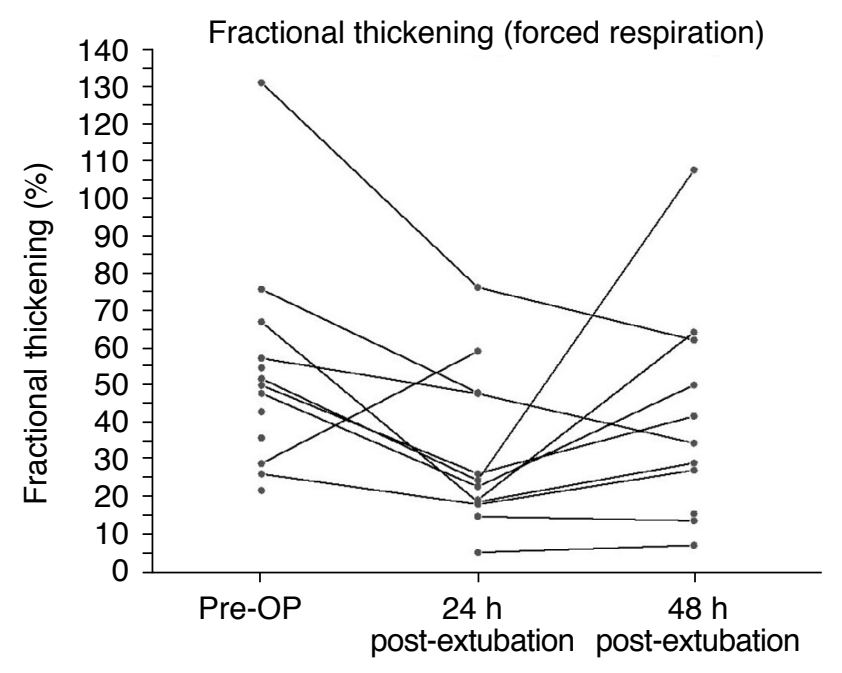

D 


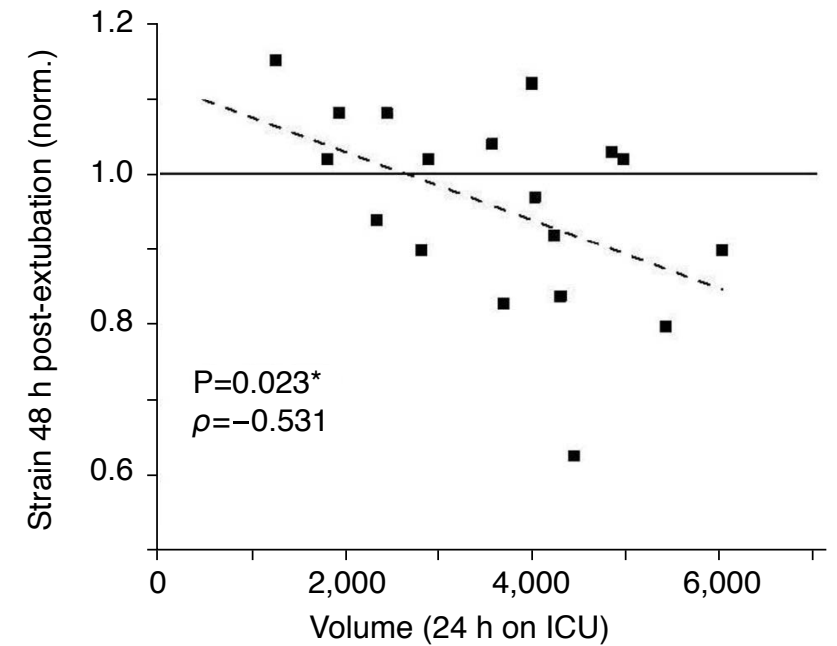

A

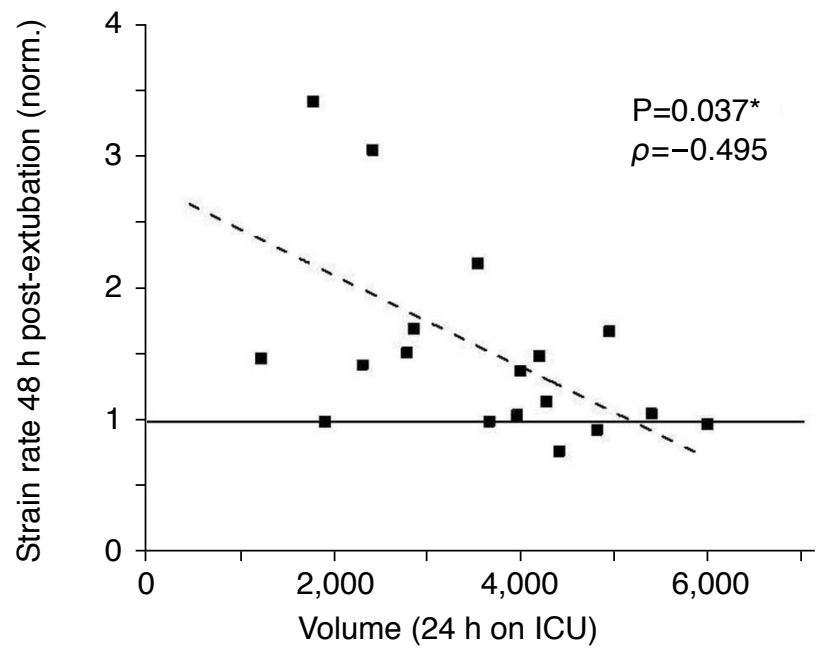

B

Fig. 7. Correlation between received fluids and diaphragmatic function 48 hours after extubation.

These scatter plots show the correlations between the strain (normalized) versus volume $(A)$ and the strain rate (normalized) versus volume (B), showing a relationship between the received fluid amount within the first 24 hours in the intensive care unit (ICU) and diaphragmatic function 48 hours after extubation, as assessed by speckle tracking analysis.

the diaphragmatic strain (deformation) during the first 24 hours after surgery. This decrease was reversed subsequently at 48 hours for both basal and forced inspiration. Previous studies showed that stepwise loading tasks were accompanied by an increase of strain, which was closely correlated to Pdi and EAdi [9]. From these data, one can conclude that reduced postoperative strain reflects decreased diaphragmatic function.

However, the strain rate showed different behaviour. We expected the strain and strain rate to change in the same direction, as we had observed before. In contrast to our expectations, the strain rate increased over time, while strain values declined. Thus, deformation of the diaphragm was reduced for about 24 hours, but the contractile velocity remained stable or even increased. A different recruitment pattern of the diaphragmatic muscle fibres could yield a possible explanation. While under basal respiration and regular load, slow-acting type I fibres account for the major part of inspiratory load, while the recruitment of fast-acting type II fibres increases as the work of breathing increases to raise contractility [18]. The rising strain rate might reflect an increasing activation of type II fibres due to a higher respiratory workload. Remarkably, this higher workload did not result in noticeably higher diaphragmatic deformation represented by strain.

As shown by the strain measurements, patients' respiratory patterns apparently recovered over time. However, some patients still seemed to require a higher muscular force to maintain sufficient ventilation, as represented by a persistently increased strain rate. If further examinations confirm these findings, an increase in the strain rate could represent an early sign of increased respiratory load and its early discovery could help to prevent diaphragmatic exhaustion. Despite these explanatory approaches, the present data are not yet fully clear and require further studies in this area.

\section{Interaction between Fluid Status and Ultrasound Parameters} There is growing evidence that a restrictive fluid balance is associated with better outcomes in critically ill patients $[19,20]$. Our data suggest that impairment of the diaphragm may be a contributing factor to these findings. They indicate that a higher administered fluid volume within the first 24 hours in the ICU impairs diaphragmatic contraction, as represented by strain and strain rate reduction. To the best of our knowledge, there are no data about the influence of the fluid balance on diaphragmatic function.

\section{Fractional Thickening}

While several authors have described close correlations between FT and diaphragmatic function [21-24], others have found no meaningful relationships [9,25-28]. In our study, FT decreased after surgery, similar to the strain and strain rate. The mean values subsequently approached the preoperative value, but the value dispersion increased. Previous publications have reported a wide span for the default values of $\mathrm{FT}$, ranging from near $0 \%$ up to $80 \%$ $[22,24,29]$. In our study, FT ranged from $4.5 \%$ up to $53.4 \%$ under basal respiration, despite a clearly defined examination protocol and careful placement of the transducer in the same anatomical 
region. Moury et al. [30], who examined patients after cardiac surgery, found a pattern for FT that was similar to our findings, with a decrease in $\mathrm{FT}$ from $36 \%$ preoperatively to $12 \%$ on the first postoperative day, which even exceeds the decrease in our study. Importantly, several patients in the latter study showed a higher FT postoperatively than preoperatively.

Other authors have used the FT to predict successful extubation, defining a cut-off value of $30 \%$ or $36 \%$ respectively $[21,22]$. In contrast, $84.2 \%(16 / 19)$ of our examined patients already had a preoperative FT value below $30 \%$. Moreover, all patients except one had an FT below the described cut-off value in the first postoperative assessment, and no included patients required reintubation. Additionally, the work of Vivier et al. [28], who also defined an $\mathrm{FT}<30 \%$ as diaphragmatic dysfunction, was not able to predict successful weaning using FT and diaphragmatic excursion. In summary, these findings indicate a meaningful inconsistency in this parameter. In the authors' opinion, it is doubtful whether a parameter with such diverging results in different studies can be useful for clinical evaluations [9].

\section{Limitations of the Study}

We did not perform any invasive measurements, such as Pdi or EAdi, because the relationship between these parameters and the speckle tracking parameters has been tested before [9]. However, a group of young healthy volunteers, as in the above-mentioned study, might not be fully comparable to CABG patients. Several patients in our study did not tolerate a repeated assessment of a forced inspiration manoeuvre. These circumstances impaired image acquisition, so image quality did not allow a sufficient analysis in all patients.

All measurements were carried out by the same examiner, who was well trained and supervised. Nevertheless, a hidden, recurrent methodical weakness in data acquisition cannot be excluded completely. Variance in the analysed diaphragm area cannot be ruled out as well, although minor variance in the investigated sector may be negligible as the contraction pattern of neighbouring diaphragm parts may be comparable.

An obstacle was the use of the speckle tracking algorithm, which was designed for the analysis of the myocardium. In some cases, the algorithm failed to track the tissue sufficiently due to differences in the texture. It was therefore necessary to adjust or redefine the ROIs a few times until correct tracking could be achieved. This issue was also observed in a previous study [8]. Thus, development and validation of custom-built software specialized for assessment of diaphragmatic muscular tissue are of the utmost importance. An online analysis tool as an additional function could also improve the usability of this method.
ORCID: Sebastian Johannes Fritsch: https://orcid.org/0000-0002-8350-8584; Nima Hatam: https://orcid.org/0000-0002-4466-9959; Andreas Goetzenich: https://orcid.org/0000-00023652-7766; Gernot Marx: https://orcid.org/0000-0003-0866-4234; Rüdiger Autschbach: https://orcid.org/0000-0002-9581-0289; Leo Heunks: https://orcid.org/0000-0003-31964665; Johannes Bickenbach: https://orcid.org/0000-0002-0039-8448; Christian Simon Bruells: https://orcid.org/0000-0002-2403-6206

\section{Author Contributions}

Conceptualization: Fritsch SJ, Hatam N, Goetzenich A, Bickenbach J, Bruells CS. Data acquisition: Fritsch SJ, Hatam N, Bruells CS. Data analysis or interpretation: Fritsch SJ, Hatam N, Heunks L, Bickenbach J, Bruells CS. Drafting of the manuscript: Fritsch SJ, Hatam N, Bickenbach J, Bruells CS. Critical revision of the manuscript: Fritsch SJ, Hatam N, Goetzenich A, Marx G, Autschbach R, Huenks $L$, Bickenbach J, Bruells CS. Approval of the final version of the manuscript: all authors.

\section{Conflicts of Interest}

N. H. received technical support from GE Healthcare. All remaining authors have declared no conflicts of interest.

\section{Acknowledgments}

We would like to express our sincere thanks to András Keszei for his assistance in the statistical analysis of this study. We would also like to thank Giulia Musetti for her preparatory ultrasound scans.

\section{Supplementary Material}

Supplementary Fig. 1. Speckle tracking analysis of the diaphragm of a single patient at different time points. The depicted analyses correspond to Video clips 2-4. This figure shows three screenshots of the Q-analysis tool of the EchoPac software depicting the strain values of the different regions of interest over the course of one breathing cycle. A-C. The preoperative assessment (Video clip 2), the assessment 7:40 hours (Video clip 3) and 35:45 hours (Video clip 4) after extubation are shown from top to bottom (https:// doi.org/10.14366/usg.21044).

Video clip 1. Representative example of a speckle tracking analysis of the diaphragm. The cineloop shows the representative speckle tracking analysis of an ultrasonographic image of the diaphragm (https://doi.org/10.14366/usg.21044.v001).

Video clip 2. Example of the preoperative speckle tracking analysis of the diaphragm. The cineloop shows the speckle tracking analysis of the diaphragm of a single patient at different time points (Video clips 2-4). Video 2 shows the preoperative evaluation (https:// doi.org/10.14366/usg.21044.v002). 
Video clip 3. Example of the first postoperative speckle tracking analysis of the diaphragm. The cineloop shows the speckle tracking analysis of the diaphragm of a single patient at different time points (Video clips 2-4). Video 3 shows the evaluation 7:40 hours after extubation (https://doi.org/10.14366/usg.21044.v003).

Video clip 4. Example of the second postoperative speckle tracking analysis of the diaphragm. The cineloop shows the speckle tracking analysis of the diaphragm of a single patient at different time points (Video clips 2-4). Video 4 shows the evaluation 35:45 hours after extubation (https://doi.org/10.14366/usg.21044.v004).

\section{References}

1. Matamis $D$, Soilemezi E, Tsagourias $M$, Akoumianaki E, Dimassi $S$, Boroli $F$, et al. Sonographic evaluation of the diaphragm in critically ill patients: technique and clinical applications. Intensive Care Med 2013;39:801-810.

2. Orde SR, Boon AJ, Firth DG, Villarraga HR, Sekiguchi H. Diaphragm assessment by two dimensional speckle tracking imaging in normal subjects. BMC Anesthesiol 2016;16:43.

3. D'Hooge J, Heimdal A, Jamal F, Kukulski T, Bijnens B, Rademakers $F$, et al. Regional strain and strain rate measurements by cardiac ultrasound: principles, implementation and limitations. Eur J Echocardiogr 2000;1:154-170.

4. Waldman LK, Fung YC, Covell JW. Transmural myocardial deformation in the canine left ventricle: normal in vivo threedimensional finite strains. Circ Res 1985;57:152-163.

5. Helle-Valle T, Crosby J, Edvardsen T, Lyseggen E, Amundsen BH, Smith $\mathrm{HJ}$, et al. New noninvasive method for assessment of left ventricular rotation: speckle tracking echocardiography. Circulation 2005;112:3149-3156

6. Perk G, Tunick PA, Kronzon I. Non-Doppler two-dimensional strain imaging by echocardiography: from technical considerations to clinical applications. J Am Soc Echocardiogr 2007;20:234-243.

7. Goutman SA, Hamilton JD, Swihart B, Foerster B, Feldman EL, Rubin JM. Speckle tracking as a method to measure hemidiaphragm excursion. Muscle Nerve 2017;55:125-127.

8. Hatam N, Goetzenich A, Rossaint R, Karfis I, Bickenbach J, Autschbach $R$, et al. A novel application for assessing diaphragmatic function by ultrasonic deformation analysis in noninvasively ventilated healthy young adults. Ultraschall Med 2014;35:540-546.

9. Oppersma E, Hatam N, Doorduin J, van der Hoeven JG, Marx G, Goetzenich $A$, et al. Functional assessment of the diaphragm by speckle tracking ultrasound during inspiratory loading. J Appl Physiol (1985) 2017;123:1063-1070.

10. Ye $X$, Xiao H, Bai W, Liang Y, Chen M, Zhang S. Two-dimensional strain ultrasound speckle tracking as a novel approach for the evaluation of right hemidiaphragmatic longitudinal deformation. Exp Ther Med 2013;6:368-372.

11. Clergue F, Whitelaw WA, Charles JC, Gandjbakhch I, Pansard $J L$, Derenne JP, et al. Inferences about respiratory muscle use after cardiac surgery from compartmental volume and pressure measurements. Anesthesiology 1995;82:1318-1327.

12. Diehl JL, Lofaso F, Deleuze P, Similowski T, Lemaire F, Brochard L. Clinically relevant diaphragmatic dysfunction after cardiac operations. J Thorac Cardiovasc Surg 1994;107:487-498.

13. Benjamin JJ, Cascade PN, Rubenfire M, Wajszczuk W, Kerin NZ. Left lower lobe atelectasis and consolidation following cardiac surgery: the effect of topical cooling on the phrenic nerve. Radiology 1982;142:11-14.

14. Pasero D, Costamagna A, Marchisio A, Pivetta E, Giunta M, Fanell $V$, et al. Diaphragmatic dysfunction following cardiac surgery: observational study. Eur J Anaesthesiol 2019;36:612-613.

15. Tralhao A, Cavaleiro P, Arrigo M, Lopes JP, Lebrun M, Rivas-Lasarte $M$, et al. Early changes in diaphragmatic function evaluated using ultrasound in cardiac surgery patients: a cohort study. I Clin Monit Comput 2020;34:559-566.

16. Tulla H, Takala J, Alhava E, Huttunen H, Kari A, Manninen H. Respiratory changes after open-heart surgery. Intensive Care Med 1991;17:365-369.

17. Harper CJ, Shahgholi L, Cieslak K, Hellyer NJ, Strommen JA, Boon AJ. Variability in diaphragm motion during normal breathing, assessed with B-mode ultrasound. J Orthop Sports Phys Ther 2013:43:927-931.

18. Mantilla CB, Sieck GC. Phrenic motor unit recruitment during ventilatory and non-ventilatory behaviors. Respir Physiol Neurobio 2011;179:57-63.

19. Besen BA, Gobatto AL, Melro LM, Maciel AT, Park M. Fluid and electrolyte overload in critically ill patients: an overview. World J Crit Care Med 2015;4:116-129.

20. Upadya A, Tilluckdharry L, Muralidharan V, Amoateng-Adjepong Y, Manthous CA. Fluid balance and weaning outcomes. Intensive Care Med 2005;31:1643-1647.

21. DiNino E, Gartman EJ, Sethi JM, McCool FD. Diaphragm ultrasound as a predictor of successful extubation from mechanical ventilation. Thorax 2014;69:423-427.

22. Ferrari G, De Filippi G, Elia F, Panero F, Volpicelli G, Apra F. Diaphragm ultrasound as a new index of discontinuation from mechanical ventilation. Crit Ultrasound J 2014;6:8.

23. Goligher EC, Laghi F, Detsky ME, Farias P, Murray A, Brace D, et al. Measuring diaphragm thickness with ultrasound in mechanically ventilated patients: feasibility, reproducibility and validity. Intensive Care Med 2015;41:642-649.

24. Vivier E, Mekontso Dessap A, Dimassi S, Vargas F, Lyazidi A, Thille $A W$, et al. Diaphragm ultrasonography to estimate the work of 
breathing during non-invasive ventilation. Intensive Care Med 2012;38:796-803.

25. Banerjee A, Mehrotra G. Comparison of lung ultrasound-based weaning indices with rapid shallow breathing index: are they helpful? Indian I Crit Care Med 2018;22:435-440.

26. Holtzhausen S, Unger M, Lupton-Smith A, Hanekom S. An investigation into the use of ultrasound as a surrogate measure of diaphragm function. Heart Lung 2018;47:418-424.

27. Rittayamai N, Hemvimon S, Chierakul N. The evolution of diaphragm activity and function determined by ultrasound during spontaneous breathing trials. J Crit Care 2019;51:133-138.
28. Vivier E, Muller M, Putegnat JB, Steyer J, Barrau S, Boissier F, et al. Inability of diaphragm ultrasound to predict extubation failure: a multicenter study. Chest 2019;155:1131-1139.

29. Goligher EC, Dres M, Fan E, Rubenfeld GD, Scales DC, Herridge $M S$, et al. Mechanical ventilation-induced diaphragm atrophy strongly impacts clinical outcomes. Am J Respir Crit Care Med 2018;197:204-213.

30. Moury PH, Cuisinier A, Durand M, Bosson JL, Chavanon O, Payen $J F$, et al. Diaphragm thickening in cardiac surgery: a perioperative prospective ultrasound study. Ann Intensive Care 2019;9:50. 